\title{
Young Zulu Men Perspectives on Masculinity and Sexual Behaviour In Rural Kwazulu-Natal
}

\author{
Mthiyane IN* and Dolamo BL \\ Department of Health studies, South Africa \\ *Corresponding author: Mthiyane IN, Department of Health studies, University of South Africa, South Africa
}

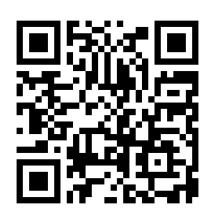

ARTICLE INFO

Received: 㝤 October 31, 2019

Published: November 14, 2019

Citation: Mthiyane IN, Dolamo BL. Young Zulu Men Perspectives on Masculinity and Sexual Behaviour In Rural KwazuluNatal. Biomed J Sci \& Tech Res 22(5)-2019. BJSTR. MS.ID.003822.

Keywords: AIDS; HIV; Masculinity; Rural Kwazulu-Natal; Sexual Behavior; Teenage Pregnancy; Positive Values; Young Zulu Men

Abbreviations: HPM: Health Promotion Model, KZN: KwaZulu-Natal, HIV: Human Immune Virus, HPM: Health Promotion Model, NDOH: National Department of Health

\section{ABSTRACT}

The purpose of the study was to explore and describe the positive values of masculinity and the role of a man in the prevention of HIV and AIDS and teenage pregnancy in a rural Kwazulu-Natal (KZN), South Africa. A generic qualitative, exploratory, descriptive and contextual study was conducted. Generic qualitative research is also called basic or interpretive research. The population were all Zulu men aged 18-24 years residing in a selected sub-district in uMzinyathi in KZN. Accessible population were those attending community meetings or were identified by peers. Snowball sampling was used to select participants. Twenty-one semi-structured interviews were conducted by the researcher with interview guides developed based on the Health Promotion Model (HPM). The data was transcribed verbatim in isiZulu and content analysed manually.

The findings in this study indicated that tradition and religion expected young men to avoid sexual relationships with girls until they were physically and financially mature to marry. That is when traditionalists would go through ceremonies and engage in traditional safe sex. The true meaning of isoka (having persuasive skills and therefore is loved by women) and ukuthwalwa (abduction of a woman by a man) were also revisited. The study provides knowledge on traditional isiZulu young men sexual practices both traditional and religious expectations in addition to modern methods of prevention of HIV/AIDS and teenage pregnancy. Recommendations were made to use these findings to develop responsible men in prevention of HIV/AIDS and teenage pregnancy.

\section{Introduction}

KwaZulu-Natal (KZN) province has the highest antenatal Human Immune Virus (HIV) prevalence (37.4\%) in South Africa National Department of Health [NDOH] [1]. Factors responsible for the high rate of HIV include poverty, sexual violence and the low status of women (United Nations Entity for Equality and Empowerment of Women [UN Women] [2]. The UMzinyathi District, where the study was done, is in a high HIV prevalence area. In 2012, the HIV prevalence in the area was $16-22 \%$ with a rate of $12 \%$ among females aged 15-24 years Shisana Rehle et al. [3]. Gender inequality is often a barrier to reducing the heterosexual transmission of HIV. In some societies, polygamy and many women sexual partners are considered a sign of manhood especially in KZN. International legislation to enforce gender equality has been endorsed by United Nations member states. Nevertheless, customary law, which promotes the superiority of men and undermines the rights of women, is dominant in many parts of the world. In addition, many churches use Scripture to support male dominance Gennrich [4].

Studies on masculinity do not seem to focus on the role of masculinity in prevention of transmission of HIV but on men trying to find or protect masculine identity in the face of different problems. Blackbeard et al. [5] focused on the emerging masculine identity of an HIV-positive adolescent boy in relation to hegemonic masculinity, while Lynch, Brouard et al. [6] examined the masculinity of a man living with HIV. Ndinda et al. [7] examined gendered perceptions of sexual behaviour in rural South Africa. Stern et al. [8] conducted narratives in urban and rural places in KZN, Mpumalanga, Eastern Cape, Western Cape and Gauteng provinces to men aged 18-24, 2554 and 55 years and above to explore how boys develop the identity 
as men and how men conform or resist gender norms that are harmful to their sexual and reproductive health. Gibbs, Sikweyiya et al. [9] explored how young black South African men living in informal settlements in eThekwini district, KZN, construct their masculinity to maintain dignity and respect in relationships with others.

Due to inability to secure employment they resorted to violence against and control of sexual partners and having multiple partners and violence against other men to secure respect. The main focus of the studies mentioned above was on how hegemonic masculinity increased the risk of HIV infection; how HIV infection deterred men from living as 'ideal' men, and how men emphasised masculinity and demanded respect in the face of challenges to hegemonic masculinity, such as being unemployed. The researcher was of the opinion, therefore, that there was a need to focus on positive values of masculinity to prevent HIV and AIDS and teenage pregnancy. Consequently, in this study, the researcher explored masculinity in relation to the prevention of HIV and AIDS and teenage pregnancy.

\section{Research Problem}

In South Africa, masculinity is a risk factor for contracting and transmitting HIV infection because it is associated with risky sexual behaviours, promiscuity and risk taking. Risky sexual behaviours associated with masculinity include none or inconsistent condom use, sexual violence, and risk taking Jama-Shai, et al. [10]. Fleming, et al. [11] found that male sexuality was not associated with intimacy, was uncontrollable, and associated with high-risk sexual behaviours. However, Fleming et al. [11] identified gaps for future research such as understanding context-specific masculinities and investigating positive influences of masculinity.

The high incidence of HIV/AIDS infection and teenage pregnancy occurring in South Africa, KwaZulu-Natal and uMzinyathi district in particular is of grave concern that requires increased preventative efforts. The high incidence and prevalence of HIV/ AIDS and teenage pregnancy among young women aged 15-24 years needs the associated social factors, such as gender inequality, to be addressed. In addition, targeted interventions for this age group need to be developed and implemented. Much research has been done on risky sexual behaviours that must be avoided. In the researcher's view, it is time to shift responsibility to men to prevent new HIV infections. Accordingly, the study explored young Zulu men's experiences of positive values of masculinity and how they use them to reduce HIV transmission and teenage pregnancy.

\section{Research Methodology}

A generic qualitative exploratory, descriptive and contextual study was conducted to explore the positive values of masculinity and the role of a man of essence in the prevention of HIV/AIDS and teenage pregnancy. A qualitative approach was suitable to capture the description of masculinity by the participants themselves, explorative to explore the full nature of the phenomenon, the manner in which it is manifested, and other related factors Polit, et al. [12] A descriptive study describes and portrays accurately the characteristics of specific situations and phenomena as they occur naturally Polit, et al. [12]. Contextual qualitative research seeks in-depth understanding of social phenomena within their natural settings because of their contextual significance Botma et al. [13] The study was done in the context of young Zulu men aged 18-24 years in a rural sub-district in KwaZulu-Natal.

\section{Population and Sample}

The population was young Zulu men aged 18-24 years, residing in a selected sub-district in uMzinyathi district. Twentyone participants were interviewed from the selected sub-district also including those who worked outside the selected sub-district and visiting home regularly. Young Zulu men aged 18-24 years who resided outside or visited the sub-district and Zulu men who were 25 years and older and men from other ethnic groups were excluded.

\section{Sampling and Sampling Process}

Snowball sampling was used to select participants for maximum variation, data quality and convenience Polit, et al. [12,13]. The first participants were asked to select participants that they thought were knowledgeable, met the inclusion criteria, and had different occupations and age groups.

\section{Data Collection}

The researcher conducted semi-structured interviews which were recorded with two digital voice recorders. The researcher and research assistant also kept field notes. Data was collected at participant homes using an interview guide based on the health promotion model HPM theoretical propositions namely perceived benefit of action, perceived self-efficacy, and perceived barriers to action, interpersonal influences, and commitment to carry out activity and immediate competing demands.

\section{Scientific Rigour}

Scientific rigour is concerned with the trustworthiness of the study. Trustworthiness is "the degree of confidence that qualitative researchers have in their data, using the strategies of "credibility, dependability, confirmability, and transferability" [12].

\section{Credibility}

In this study credibility was achieved by utilising field notes, voice recordings, transcripts and sampling till category saturation occurred. The researcher also validated interpretation of what the participant was saying by paraphrasing, repeating what the participant had said and asking for clarity and transcribing verbatim.

\section{Transferability}

Transferability was ensured by means of sampling participants with different characteristics of age, employment and marital status for interviews. 


\section{Dependability}

Dependability was ensured by doing a pilot study and keeping an audit trail. A pilot study to test the feasibility of the proposed main study and to reveal unexpected problems in the tool such as ambiguity and inadequate time limits was done. The data of the pilot study was analysed with those of the main study, however, the participants were excluded from the main study sample.

\section{Confirmability}

Presenting a detailed description of research process and keeping field notes was used to ensure confirmability.

\section{Ethical Considerations and Ethical Principles}

The goal of ethics in research is to ensure that no one is harmed from research activities Polit, et al. [12]. In this study, the researcher obtained permission HSHD/566/2016 to conduct the study from the University of South Africa, the KZN Department of Health (HRKM 100/17 KZ_2017RP38_742), the chief (Inkosi) and the headmen (Izinduna); obtained informed consent from the participants. The ethical principles of respect for human dignity, beneficence, and justice Polit, et al. [12]. were upheld. The results were a true reflection of what the participants said and there was no fabrication, falsification, exaggeration or manipulation of the data or findings Botma et al. $[13,14]$.

\section{Data Analysis}

Data were analysed thematically and manually. Six data analysis steps were followed Creswell [15]. Organization and preparation of data including transcribing interviews (Step 1); reading all transcripts to get ideas, tone and impression of what was said by participants, and writing thoughts about data in the margin (Step 2); coding (step 3); generation of themes (Step 4); description of how themes were used to convey findings (Step 5) and interpretation of findings from narratives of participants (Step 6).

\section{Research Results}

The findings revealed subthemes pertaining to avoidance or delaying sex such as avoid premarital sex, alternative ways to demonstrate love, wait for traditional ceremonies, avoid abduction of women, non-penetrative sex and choose a lover or girl to marry.

\section{Avoiding Relationships and Premarital Sex}

One participant stated: "It is wrong to engage in premarital sex; fornicators will not see the kingdom of God." Participants felt that breaking up was something that had to be done as one stated: "There are those things that you do not get rid of easily, yes, it is difficult, but I hope I will pass through this. It is difficult to separate with her but trusting God to help me I hope to pass this... maybe it will help to drop her because she might pressurise me. Maybe it will help me to leave her." Another reason for avoiding relationships seemed to be the expectation to have sex if one is in a relationship as one young man stated: "There are things you can do and things you cannot do. So, I avoid all don'ts as ... once you are in a relationship in the long run you will end up there."

Participants went on to say that even in non-Christian religion they were not expected to get into a relationship as one participant stated: "How do we behave madam, you see in the church where (I do not usually go) but my family madam, religiously they are not allowed (to be in relationships)." Engaged couples were also included in the avoidance of sex during the marriage negotiation process as one stated the following: "Even when they are engaged, they should be able to control themselves and wait until they get married." Another option was meeting their girlfriends in public spaces in order to be safe from temptation as one stated: "A woman can pressurise you to have sex ... I try to meet her in public spaces." One young man in this study described Isoka as having nothing to do with sex as follows: "Isoka is a man who is known for his ability to persuade women to be in a relationship with him. It had nothing to do with sex." In this study avoidance of sleeping together in a relationship included sex not being a priority, avoiding it even during negotiations of bridal price (lobola) including and not visiting each other and as a result they would be few teenage pregnancies: "Sleeping with her was not a priority even after he had started the negotiations. The girl's family would make sure that she sleeps at home every night until the negotiations and the bride price has been paid then she was allowed to go and marry."

In this study Christians agreed to be in a relationship with a Christian: "Ok I see that when we have found grace when we now believe, you have been lucky. You must be in a relationship with a woman who is a believer." Choosing a partner of the same faith concurred with the biblical principle in 2 Corinthians 6:14 2 Kings 6:11 "Do not be unequally yoked" [16]. Non-Christian believers and traditionalists agreed on befriending or having a relationship with a person of same mind. Some participants stated: "You must be friends with people who have the same goals as yours in life because if not they may lead you astray." "It will have to be according to the tradition that if I love her to do according to my way madam. If she does things her way, there will be no harmony."

\section{Alternative Ways to Demonstrate Love}

Believers and traditionalists in this study agreed that sex is not the only way one can demonstrate love to his girlfriend as one participant stated: "I say love is not something that you say with your mouth but actions should show love. If there is a problem maybe she has run out of toiletries... I give her."

\section{Wait for Traditional Ceremonies}

Participants said that ceremonies such as the rites of passage help to delay starting relationships with girls and intimacy. Some participants in this study stated: "She must have finished school and at least 20 years old and has had traditional ceremonies such as umhlonyane and umemulo." In this study participants said a ceremony is done after choosing a lover and there would be no 
visiting each other before it is done as a participant stated: "They will not visit each other until they have had another traditional ceremony that is when they will start sleeping together, but before that ceremony they do not sleep together. If they start their relationship like that, it is forever." According to Turner [17]. Umhlonyane is a traditional Zulu ceremony to celebrate a girl's first menstruation. Ten years later follows umemulo (coming of age) which is a ceremony to acknowledge that a girl is old enough to get married. According to Maureau [18]. the journey to marriage for the couple involves a series of traditional ceremonies that involve exchanges of gifts until they are allowed to be together. After the above mentioned ceremony another exchange of gifts ceremony is held after which the girl may visit her fiancé as stated by one participant: "After some time the girls family brings a letter in which they write, maybe one needs this and another that These things are bought and sent... after that the girl can visit."

\section{Avoid Abduction of Women}

Participants stated: "I do not think it is right, she has never talked to him, they just say here is the person that we have found for you ...she has to agree because the elders have said so."

\section{Non- Penetrative Sex}

Some participants mentioned traditional non-penetrative way of sexual satisfaction called ukusoma as they stated: "Ukusoma is when you have sex, but you do not use that part (vagina). Some say in the thighs and in the breasts, things like that."

\section{Choose A Lover and or Choose A Girl to Marry}

According to participants traditionally a relationship becomes official when the couple announce it known to the parents and the community by raising a flag (ukuqoma ngeduku) at the man's home which signifies permanence of the relationship and intentions to marry: "It means she is your person, you have chosen each other, you will be with her until death or until you pay the bride price and marry." Religious choosing of a partner was described as meaning the same thing as the traditional ukuqoma. However, one has to wait until one is physically and financially ready to marry. Participants mentioned practices in different denominations, Christian and nonChristian. "Christians, the ones that say they are saved madam, ... they absolutely do not get into relationships at all. When they are supposed to get married, oh madam, ... I think they choose each other in the church where they worship."

\section{Theoretical Foundation}

The researcher selected Pender's [19] Health Promotion Model (HPM) which focuses on promoting health through a wellness orientation as the foundation of the study. The HPM describes factors in context that influence health behaviour on which nurses and other health workers can base counselling to promote healthy behaviour. It can be used to prevent situations that interfere with health promoting behaviour and promote healthy behaviours Polit and Beck [12].

\section{Discussion}

The findings reflect that tradition and religion expect young men to avoid relationships until fully grown and ready to marry. The boys and girls do not feel pressurised to sexual debut at an early age and chances of multiple partners are also reduced. According to Nelson [16], in 1 Corinthians 6 verse 9, Christians base avoidance of premarital sex on avoidance of fornication. Traditional avoidance of penetrative vaginal sex before marriage is a sign of respect for the girl and the father of the young man who taught him to respect girls' virginity. According to the Zulu tradition young girls and boys would be allowed to start ukusoma (interfemoral sex) by iqhikiza (peer adviser / educator) after they had received education about a variety of alternative sexual practices without penetration Maureau [18]. When a young man came to visit his girlfriend at night (without parent's knowledge), he would be met by the girl's older sister who would take him to a vacant hut where he was going to spend the night with his girlfriend. The girl's older sister would tell the boy to behave himself meaning that he must not have penetrative sex with the girl. The girl would also be warned by her sister to protect her virginity when she would tell her not to "expose (their) fathers' cattle (ungazeneki izinkomo zikababa)" [18]. Sexual satisfaction without penetration reduces risk of transmission of HIV provided that the skins of both partners are intact.

According to Zulu culture education of boys and girls about sexuality rules was done by elder women and elder men during puberty rituals through songs, dances and talks. Another source of information was older sisters and older brothers for girls and boys respectively. They listened to their siblings' discussions and advisors who talked openly about courting and watched courting couples to gain skills. Sexual experimentation without penetration such as ukusoma was taught by iqhikiza Maureau [18]. Before marriage the couple may be intimate by practicing ukusoma to protect the girl's virginity. It is not considered as sex in Zulu culture and respecting the girl's virginity is also a sign of respect for young man's father who taught him to respect girls' virginity Maureau [18]. The following is a description of ukusoma: The girl lies on left lateral position with legs crossed and thighs very tight together so that the penis ends at the clitoris. She catches semen with the left hand and wipes it over the thigh and leg until dry Maureau [18].

A man with persuasive skills (Isoka) is included in respecting the girls' virginity. According to Hunter [20]. Isoka refers to a man who is popular with women. In the 1800 s when a young man could not afford to get married and become a respected man (umnumzane) he proved his masculinity by having many girlfriends. However, there was no penetrative sex with them Hunter [21]. In the 1940s the word Isoka evolved to mean a man with many sexual partners, however, he would eventually marry all of them Hunter [21]. In 1970 the word meant that the man had many girlfriends and was not expected to marry any of them. Today a man with many sexual partners receives the same respect as a man who had many wives in the 1940s Maureau [18] Hunter, [21-23]. According to Gennrich 
[4] traditional values of masculinity such as ubusoka (having many girlfriends) became distorted after colonialism to become equated with having many sexual partners. In the pre-colonial era ubusoka did not allow penetrative sex.

According to Gennrich [4] ukuthwala (abduction of a girl to marry) was voluntary. The girl would be involved in planning her abduction to the man she wanted to marry and would not be coerced to have sex. There is scarcity of literature regarding prevention of HIV and AIDS and teenage based on masculinity. Most studies focus on the contribution of masculinity to fuelling the HIV epidemic and teenage pregnancy. In the South African context the historical, social and cultural factors that shaped what it means to be a man contributed to teenage pregnancy and transmission of HIV and AIDS Gennrich [4] However, in this study the results from the semi-structured interviews revealed that traditional and religious background may help to develop a masculinity that promotes HIV preventing behaviours.

\section{Study Limitations}

Data collection was limited only to semi-structured interviews and the researcher perceptual misinterpretations were limitations of this study. Same sex interviews by a person of more or less of the same age group might have produced more information that was not mentioned Data depended on recall and truthfulness.

\section{Conclusion}

The researcher found no research on the positive values of masculinity in the prevention of HIV and teenage pregnancy. This study is a steppingstone to addressing the context of HIV and AIDS transmission and teenage pregnancy from a masculine and positive perspective.

\section{Recommendations}

Recommendations are made to managers, health care workers and community leaders including parents and church leaders to introduce youth and community conversation programs on sex and sexuality, including parenting of boys for prevention of HIV and teenage pregnancy.

\section{Acknowledgement}

Our sincere gratitude goes to all those contributed: The University of South Africa for funding, the editors for professionally and technically finalizing the manuscript and the participants for their sincerity and time to share their stories.

\section{References}

1. (2013) National Department of Health (NDOH). South African antiretroviral treatment guidelines, 2013. The national Department of Health, Pretoria, South Africa.

2. (2016) United Nations Entity for Gender Equality and the Empowerment of Women (UN Women). Facts and figures: HIV and AIDS prevalence and new infections. UNAIDS, Geneva, Switzerland.
3. Shisana O, Rehle T, Simbayi LC, Zuma K, Jooste S, et al. (2014) South African national HIV prevalence, incidence and behaviour survey.

4. Gennrich D (2013) Men and masculinities in South Africa, understanding masculinity in South Africa - essays and perspectives. Sonke Gender Justice Network, Pietermaritzburg, South Africa, 2.

5. Blackbeard D, Lindegger G (2014) Dialogues through autography: young masculinity and HIV identity in KwaZulu-Natal. The European Journal of Social and Behavioural Sciences pp. 2301-2218.

6. Lynch I, Brouard PW, Visser MJ (2010) Construction of masculinity among a group of South African men living with HIV: reflections on resistance and change. Culture, Health and Sexuality 12(1): 15-27.

7. Ndinda C, Uzoduke, UO, Chimbwete C, Mgeyane MTM (2011) Gendered perceptions of sexual behaviour in rural South Africa. International Journal of Family Medicine (2011): 973706.

8. Stern E, Clarfelt A, Buikema R (2013) The relational dynamics of hegemonic masculinity among South African men and women in the context of HIV/AIDS. Culture, Health and Sexuality 15(9): 1040-1054.

9. Gibbs A, Sikweyiya Y, Jewkes R (2014) Men value their dignity: securing respect and identity construction in urban informal settlements in South Africa. Global Health Action 7: 23676

10. Jama Shai N, Jewkes P, Nduna M, Dunkle K (2012) Masculinities and condom use patterns among young rural South African men: a crosssectional baseline survey randomised controlled trial. Public Health 12 : 462 .

11. Fleming PJ, DiClemente RJ, Barrington C (2016) Masculinity and HIV: dimensions of masculine norms that contribute to men's HIV-related sexual behaviours. AIDS and Behaviour 20(4): 788-798.

12. Polit DF, Beck CT (2014) Essentials of nursing research: appraising for nursing practice. $\left(8^{\text {th }} \mathrm{Edn}\right)$. Wolters Kluwer, Philadelphia, USA.

13. Botma Y, Greeff M, Mulaudzi FM, Wright SCD (2010) Research in health sciences. Pearson Education, Cape Town, South Africa.

14. Polit DF, Beck CT (2017) Nursing research: generating and assessing evidence for nursing practice. $\left(10^{\text {th }} \mathrm{Edn}\right)$ Wolters Kluwer, Philadelphia, USA.

15. Creswell JW (2014) Research design: Qualitative, quantitative and mixed methods approach. ( $4^{\text {th }}$ Edn). London, UK.

16. Nelson T (1982) The Maxwell leadership Bible. New King James Version. 2 Corinthians 6: 14-16.

17. Turner $\mathrm{N}$ (2018) Humor and scatology in contemporary ceremonial songs. Humor 31(2): 1-165.

18. Maureau EA (2014) The negotiation of HIV prevention among community HIV educators in KwaZulu-Natal, South Africa.

19. Pender N (2011) The health promotion model manual. University of Michigan, Ann Arbor MI, USA.

20. Hunter M (2004) Masculinities, multiple-sexual-partners, and AIDS: the making and unmaking of Isoka in KwaZulu-Natal. Transformation 54: 123-153.

21. Hunter M (2005) Cultural politics and masculinities: multiple partners in historical perspective in KwaZulu-Natal. Culture, Health and Sexuality 7(4): 389-403.

22. Andrew Gibbs, Yandisa S, Rachel J (2014) Men value their dignity': securing respect and identity construction in urban informal settlements in South Africa $7(1)$.

23. (2016) World Health Organisation (WHO). Consolidated guidelines on the use of antiretroviral drugs for treating and preventing HIV infection. WHO, Geneva, Switzerland. 
ISSN: 2574-1241

DOI: 10.26717/BJSTR.2019.22.003822

Mthiyane IN. Biomed J Sci \& Tech Res

(C) This work is licensed under Creative

Submission Link: https://biomedres.us/submit-manuscript.php

$\begin{array}{ll}\text { BIOMEDICAL } & \text { Assets of Publishing with us } \\ \text { RESEARCHES } & \text { - Global archiving of articles } \\ & \text { - Immediate, unrestricted online access } \\ & \text { - Rigorous Peer Review Process } \\ \end{array}$

